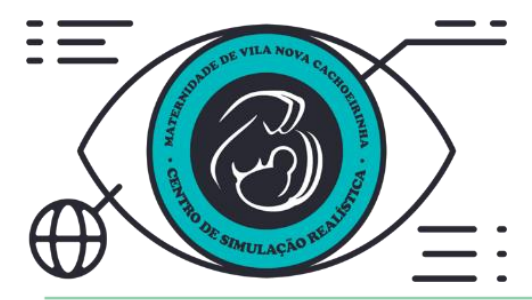

\title{
Quali HOSP
}

\section{ESTRUTURAÇÃO DE POLO CAPACITADOR EM SIMULAÇÃO REALÍSTICA:}

Inovação na Rede Pública do Município de São Paulo

Autores: Pedro Alexandre Federico Breuel Simone Pereira Vidotti

Maria Lucia Bom Angelo Claudia Tanuri 


\section{INTRODUÇÃO}

-"Primum non nocere" - Primeiro não prejudicar Não maleficência - Hipócrates 3 AC

- 45 a 98 mil pacientes que morrem por erros durante a hospitalização nos Estados Unidos;

TO ERS IS HUIMAN

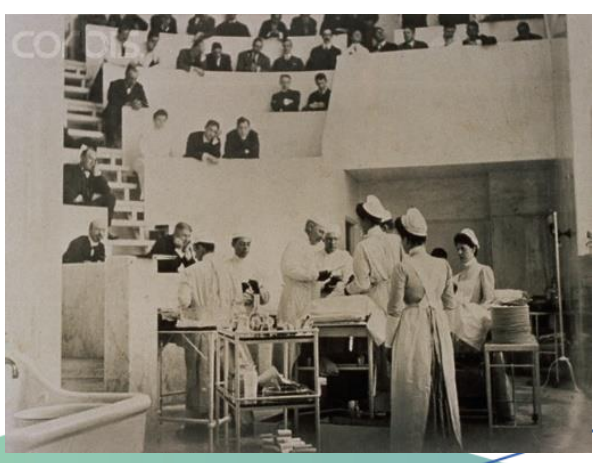

Modelo

Competências

Halstediano 


\section{INTRODUÇÃO}

- Refletindo sobre o cenário nacional segurança do paciente surgiu a preocupação de como o corpo clínico e estudantes ( graduação e pós-graduação) na área da saúde estão sendo treinados para diminuir danos aos pacientes;

Relatório sugere incorporação SIMULAÇÃO REALÍSTICA

HIPÓTESE: Estruturar um polo capacitador para prestadores de serviço na saúde da Rede Municipal de São Paulo diminuirá danos aos pacientes, podendo melhorar a assistência prestada. 


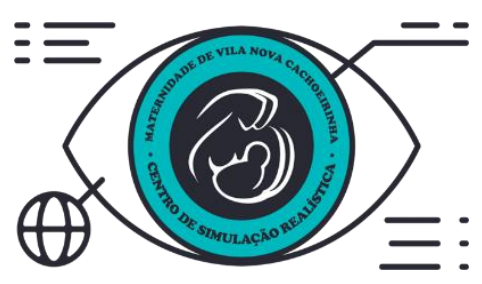

OBJETIVO GERAL

Estruturar polo capacitador em assistência a saúde para profissionais na Rede Pública Municipal de Saúde de São Paulo utilizando Simulação Realística

\section{OBJETIVO ESPECÍFICO}

1) Descrever as etapas para estruturação de um polo capacitador utilizando Simulação Realística;

2) Identificar estratégias para capacitar corpo clínico para utilização deste método de ensino;

3) Definir parcerias para obtenção de recursos materiais e estruturais utilizados na Simulação Realística. 


\section{PERCURSO METODOLÓGICO}

- Local: Hospital Municipal e Maternidade Escola Dr Mario de Moraes Altenfelder Silva. Terciário em Neonatologia e Obstetrícia. Secundário para Ginecologia;

- Hospital de Ensino desde 2011: qualidade assistência e ensino e pesquisa;

- As etapas para a estruturação ocorreram em dois eixos: Capacitação e Estrutural. 


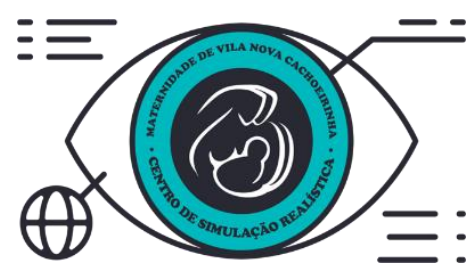

\section{RESULTADO EIXO CAPACITAÇÃO}

1) Curso para formação de instrutores em Simulação Realística: parceria com instituição privada ( Essencials of Simulation) Conceito de Andragogia, Construção de Cenários, Como realizar Debriefing - 25/9/17
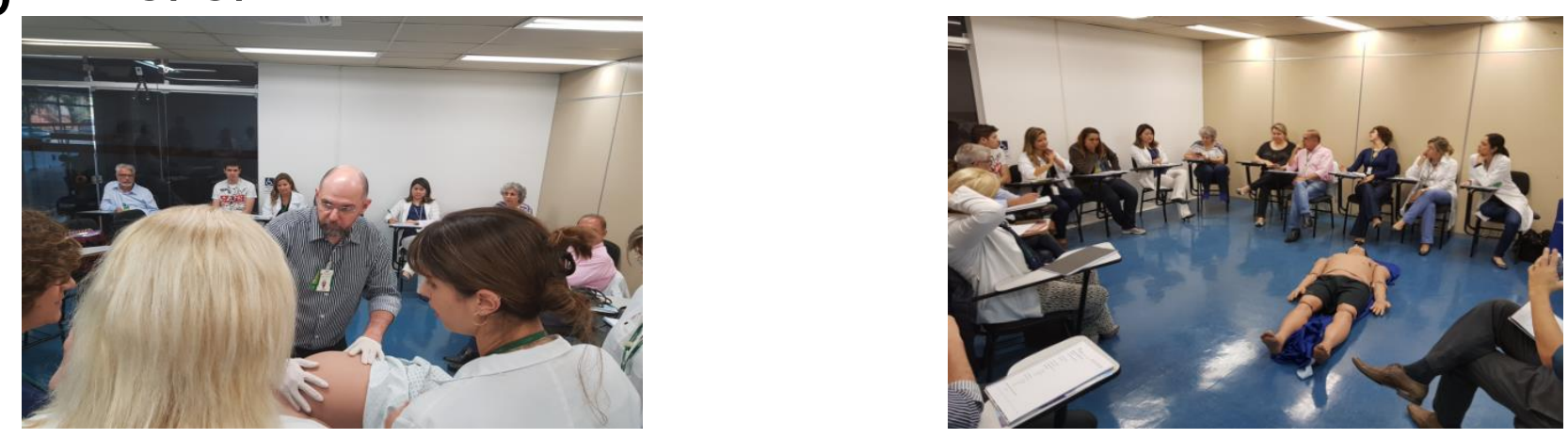

2) 1 Jornada de Simulação Realística $(26 / 9 / 17)$ : Temas Realística no Ensino em Saúde na Era Pós Digital, Atividades de Simulação Realística (Simuladores no Treinamento em Saúde e Recursos Tecnológicos para o treinamento de habilidades); 


\section{RESULTADO \\ EIXO CAPACITAÇÃO}

3) Il Semana de Ensino 2108 tema "Errar é humano: A Simulação Realística como estratégia para lidar com esse paradigma"

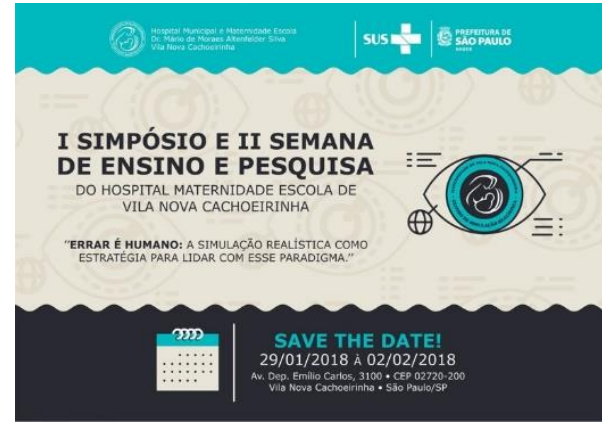

4) Criação de Comissão Centro de Simulação ( 6/10/17) com publicação 19/1/18 portaria n 6/2018 - GAB DIR. Com reuniões mensais a partir da sua criação visando estratégias e soluções para efetivação dos cenários.

5) Visitas em Centros de Simulação privados (Instituições e Universidades privadas); 


\section{RESULTADO EIXO ESTRUTURAL}

- Aquisição de equipamentos de Simulação, projeto arquitetônico através do COAPES (Contratos Organizativos de Ação Pública Ensino-Saúde);

- Espaço físico: Planejamento estratégico institucional para alteração de finalidade de uso de espaço; 


\section{CONCLUSÃO}

A estruturação do polo capacitador em assistência a saúde utilizando Simulação Realística é uma inovação na Rede Municipal para aumentar a segurança do paciente; 


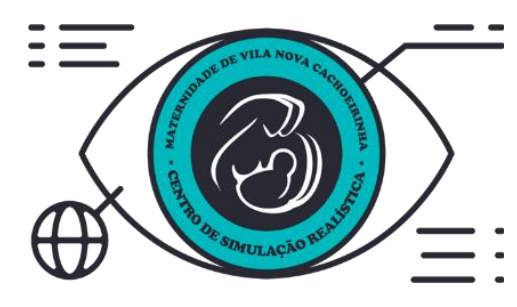

\section{Quali $\mathbb{\text { Hosp }}$}

"Foi o tempo que dedicaste a tua rosa que a fez tão importante"

Antoine de Saint - Exupéry

OBRIGADA

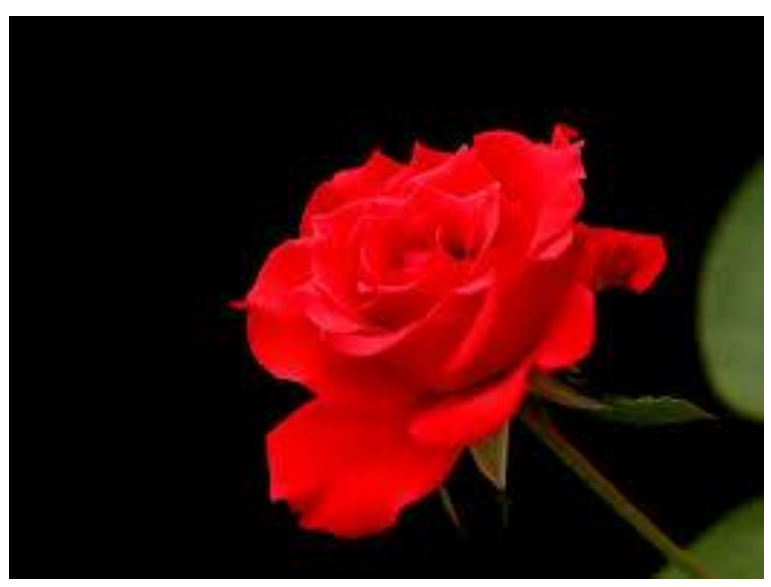

